\title{
Tourism-led growth asymmetries in Greece: evidence from quantile regression analysis
}

\author{
Sarantis Lolos ${ }^{1} \cdot$ Panagiotis Palaios ${ }^{2}$ - Evangelia Papapetrou ${ }^{2,3}$
}

Received: 17 July 2020 / Accepted: 18 January 2021 / Published online: 24 March 2021

C ISEG - Instituto Superior de Economia e Gestão 2021

\begin{abstract}
The paper provides fresh empirical evidence on the tourism-growth relationship for Greece over the period 1977Q1-2020Q2. We find that the long-run relationship between tourism and output is positive and is characterized by a substantially faster adjustment of output after a negative shock than after a positive one. Using asymmetric error-correction model analysis the results show that the short-term adjustment path occurs through the level of output for negative deviations from the longrun equilibrium, thus supporting the tourism-led growth hypothesis. Linear quantile regression $(\mathrm{QR})$ analysis indicates that the impact of tourism remains positive across the output distribution, but the effect is more pronounced at the lower quantiles of output while at the higher quantiles of output it becomes weaker and statistically insignificant. Furthermore, applying asymmetric QR analysis there is evidence that tourism growth exhibits an asymmetric impact on output growth. Our results have important policy implications, since the tourism-led growth hypothesis is a useful policy recommendation, but it should not be considered a panacea.
\end{abstract}

Keywords Tourism · Economic growth · Tourism-led growth hypothesis · Quantile regression $(\mathrm{QR})$ approach

JEL F43 $\cdot$ L83 $\cdot$ C32

\section{Introduction}

The sharp increase of tourism internationally and its rising share in GDP and employment makes the examination of its relationship with economic growth of crucial importance. The question is whether tourism acts as a driver for economic growth, or the reverse, or indeed there exists a bi-directional, or a no causality

Evangelia Papapetrou

epapapetrou@bankofgreece.gr

1 Department of Economic and Regional Development, Panteion University, Athens, Greece

2 Department of Economics, National and Kapodistrian University of Athens, Athens, Greece

3 Bank of Greece, Economic Research Department, Athens, Greece 
relationship between the two variables. Although the rapidly expanding empirical research opts for a long-run causality running from the expansion of tourism to economic growth, i.e. a "tourism-led growth" hypothesis, the issue is still unresolved. ${ }^{1}$ The results depend on the specificities of the cases studied and also on the methodology been followed.

The important interaction of tourism with economic activity has been recognized by McKinnon (1964) who put the foundations of the tourism-led growth hypothesis, which was formalized and tested empirically by Balaguer and Cantavella-Jordá (2002). It postpones that the foreign exchange earnings finance investment and differentiated production, thus promoting economic growth. Also, tourism stimulates investment in new infrastructure and increases competition thus improving efficiency of local firms (Krueger 1980; Balaguer and Cantavella-Jordá 2002). Furthermore, tourism generates employment and boosts the accumulation of human capital acting also as a catalyst in the diffusion of technical knowledge (Schubert et al. 2011). Finally, tourism can cause positive exploitation of economies of scale and scope thus decreasing production costs for local businesses (Andriotis 2002).

However, the reverse effect, the "growth-led tourism" hypothesis, is also empirically identified (e.g. Narayan 2004; Oh, 2005; Payne and Mervar 2010). A country's sustained economic growth boosts the development of tourism in this country, which in its turn creates a positive economic environment for the attraction of more international tourists. Also, several empirical studies show a bi-directional relationship between tourism and economic growth. A boost of tourism affects economic activity positively, which in its turn leads to an increase in tourism (e.g. Kim et al. 2006; Tang 2013; Massidda and Mattana 2013). Finally, some studies do not find a longrun association between the two variables (e.g. Katircioglu 2009; Jackman and Lorde 2010).

In the case of Greece, several empirical studies investigated the relationship between international tourism and the country's economic growth. In particular, Dritsakis (2004) analyzed the relationship between tourism earnings, GDP and exchange rate (1960Q1-2000Q4), using VECM (Johansen) — Granger causality tests and found that tourism causes economic growth with a "strong causal" relationship, while economic growth causes tourism with a "simply causal" relationship. Kasimati (2011) analyzed the relationship between tourist arrivals, GDP and effective exchange rate for Greece over the period 1960-2010, using VECM (Johansen)—Granger causality method and found that there is no causality between the variables. Eeckels et al. (2012) using VAR analysis showed that the cyclical component of tourism income is significantly influencing the cyclical component of GDP and validated the tourism-led economic growth hypothesis for the case of Greece over the period 1976-2004. Aslan (2013) examined the relationship between tourist receipts, exchange rate and GDP with panel cointegration and Granger causality methodology for twelve Mediterranean countries (1995-2010). He came to mixed results and for the case of Greece he found a unidirectional causality running from economic growth to tourism.

\footnotetext{
${ }^{1}$ For a review of the numerous empirical studies on the tourism-growth nexus, see, Brida et al. (2016), Comerio and Strozzi (2019), Nunkoo et al. (2019).
} 
Also, Othman et al. (2012) investigated 18 major tourist destinations worldwide including Greece, using ARDL methodology and came to mixed results. In the case of Greece, they found no causal relationship between tourism and growth. Dritsakis (2012) examined the relationship between tourist arrivals, effective exchange rate and GDP for seven Mediterranean countries including Greece (1980-2007), using panel cointegration and fully modified OLS and detected a unidirectional longrun causality running from tourism to economic growth. Antonakakis et al. (2015) examined the dynamic relationship between tourism growth and economic growth for 10 European countries over the period 1995-2012. They conclude that the tourism-economic growth relationship is not stable over time in terms of magnitude and direction. They show that this relationship is event-dependent especially in countries that encountered severe economic downturns since 2009, like Cyprus, Greece, Portugal and Spain.

Recently the investigation of the tourism-growth nexus turned to more advanced techniques with rising reliance on non-linear relations. In this context, the link between tourism and output might vary with the state of the economy (flourishing or bearish economy) and each variable may react asymmetrically to negative/positive shocks or to large/small changes in the other variable. Wang (2012) examined threshold effects on the tourism development and economic growth relationship, casting doubts on the findings implied by the existence of a linear relationship. Also, Shahzad et al. (2017) using the quantile-on-quantile (QQ) approach examined the interdependence of the tourism and output variables for ten top tourist destination countries by estimating the effects of the quantiles of tourism growth on the quantiles of the output growth. To the best of our knowledge the empirical investigation of the relationship of tourism and output in the presence of non-linearities in Greece is missing.

The purpose of this paper is to provide fresh empirical evidence on the relationship between international tourism and economic activity taking Greece as an example, a medium sized country, whose economy to a great extent relies on tourism. We studied the period 1977Q1-2020Q2, over which the development of the economy has not been particularly uniform, especially during the severe economic crisis for over a decade. Since the development of incoming tourism has not been smooth either, we believe that the tourism-output relationship might not be linear or symmetric. Furthermore, in the presence of a non-linear relationship between tourism and output policy implications and suggestions based on linear methodology may be misleading to policymaking.

Thus, we first investigate the asymmetric relationship between tourism and output using a threshold cointegration approach, while examining the adjustment in the short term via an asymmetric error-correction model estimation with threshold cointegration (Enders and Siklos 2001; Sun 2011). The findings support the tourismled growth hypothesis. The results point to an asymmetric effect behaviour both in the short and long term and to a substantial faster and significant speed of adjustment of output for negative deviations from the long-run equilibrium. Second, we apply the econometric methodology of Koenker and Bassett (1978) and Nusair and Olson (2019), namely quantile regression (QR) analysis, to examine the impact of tourism growth on output growth. Using $\mathrm{QR}$ analysis we gather information on the 
co-movements between tourism and output under various states of the economy, that is whether it is flourishing (upper quantiles), bearish (lower quantiles) or normal (intermediate quantiles). The results show that the impact of tourism remains positive and significant across the output distribution, but the magnitude of the impact is more intense at the lower quantiles of output that is in a bearish economy. Third, we implement asymmetric QR analysis providing evidence that tourism growth has an asymmetric impact on output growth, where the magnitude of the positive impact of tourism is more intense at lower states of output.

In view of the recent econometric advances, our study contributes to the tourismgrowth literature in various ways. First, by investigating the existence of a non-linear relationship between the variables through the application of a threshold cointegration and an asymmetric error-correction model. Second, by examining the effects between the variables using $\mathrm{QR}$ analysis. QR model estimation allows examining the impact of changes of one variable over a range of values of the other variable, providing a more concrete investigation of the relationship of the two variables. Third, by applying asymmetric QR analysis allowing for asymmetries between positive and negative changes of one variable on the other to acquire further insights into the complexity of their nexus. Lastly, our approach differs from the great majority of existing studies, including those for Greece, on the tourism-output relationship that investigate only linear and symmetric behaviour or study the relationship in a time varying environment.

The conclusions drawn could be useful for the analysis of other countries with similar characteristics, especially for countries that their economy has undergone significant swings during the recent economic crisis, such as some Southern and Eastern European countries. Our results leave room for national policies to operate for the promotion of economic growth.

The rest of the paper is organised as follows. Section 2 presents features of the Greek economy. Section 3 discusses the variables and analyses the data used. Section 4 presents the econometric methodology. Section 5 discusses the empirical results of the study and a robustness analysis of the results is included in Sect. 6. Finally, Sect. 7 summarises the results and concludes.

\section{Features of the Greek economy}

After the World War II the Greek economy gradually normalized, achieving internal and external stability. From the mid-1950s until the first energy crisis (1973), the economy registered unprecedented high annual growth rates of 6-7\% (Halikias 1978). After the first and until the second energy crisis (1978/9) the growth rates receded to $4-5 \%$ but afterwards and until the mid-1990s the Greek economy stagnated with annual growth rates of around $1 \%$ (Fig. 1). Over this period a great shift took place from primary and secondary sectors to the tertiary sector, although industrial and international trade policies were quite interventionist. Also, over the 1990s in view of the country joining the Euro, successful Convergence Programmes were implemented (Lolos 1998). As a result, from the mid-1990s until after the 


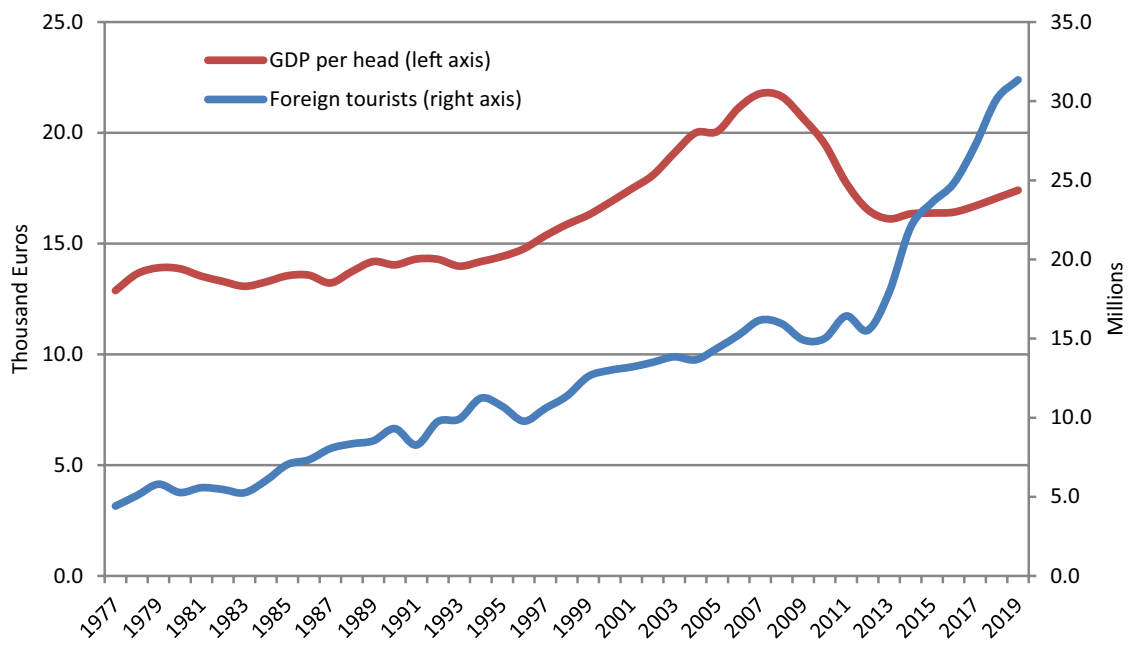

Sources: ELSTAT, EUROSTAT, Bank of Greece.

Fig. 1 Output and tourism in Greece, 1977-2019

mid-2000s the economy achieved high growth rates of around $4 \%$ per annum on average, well above those of the EU countries.

However, in the period 2007-09 there was a rapid deterioration of the internal and external balances of the Greek economy which almost coincided with the beginning of the global financial crisis (2008). In 2009, both the external imbalance and the public sector deficit rocketed to around $15 \%$ of GDP, while the public debt to GDP ratio increased to $127 \%$ from around $95 \%$ that it was in the second half of the 1990s. In 2010, the government in order to avoid default was obliged to enforce a severe structural adjustment programme which would turn into a series of adjustment programmes $(2010,2012,2015)$ mainly financed by the EU countries (European Commission 2018). Various governments that came to office were thus obliged to implement severe austerity measures for fiscal consolidation, the achievement of external balance and competitiveness improvement, including tax increases and cuts in wages, pensions and salaries. As a result, the economic activity underwent an unprecedented depression loosing around $25 \%$ of its output (2010-2017), while the rate of unemployment tripled to $28 \%$ relatively to previous periods. After 2017/8 the economy started recovering at low rates of less than $2 \%$ annually and unemployment dropped gradually to $17 \%$ in 2019 .

The post-war tourism policy was explicitly framed on the grounds of the tourismled growth hypothesis, in line with the directives of the Marshall Plan for Greece. ${ }^{2}$ Over the 1950s and 1960s the state embarked into the construction of a network

\footnotetext{
2 The Marshall Plan (officially the European Recovery Program) was an American initiative passed in 1948 for foreign aid to Western European economies after the end of World War II.
} 
of modern hotels and related tourist infrastructure, the so-called Xenia Programme (1950-74), while private investors hesitated to invest in tourism. The supply of tourist infrastructure was supplemented by a substantial state financed tourist advertising campaign.

As shown in Fig. 1, tourism activity increased sharply over the period under review (1977-2020). In the early 1970s international tourist arrivals were at low levels of 2-3 million visitors annually. However, since the mid-1970s and after first energy crisis and the fall of the dictatorship (1974), the number of foreign tourists increased at a fast pace (about $10 \%$ per year), reaching 6-7 million visitors annually in the mid-1980s. In the two-decade period from the mid-1980s to mid-2000s tourist arrivals were doubled to around 14-15 million per year. After the Athens Olympics (2004) and in conjunction with the adverse conditions in the tourist markets in Eastern Mediterranean towards the end of $2000 \mathrm{~s},{ }^{3}$ international tourist arrivals increased sharply exceeding 31 million visitors in 2019. In the period after the beginning of the Greek economic crisis (2010) positive tourism developments were facilitated by tourist market reforms giving a boost to domestic demand, greatly benefiting the struggling economy (Kasimati and Sideris 2015).

Note finally that tourism activity has always been considered a priority sector in Greece. Over the 1970s and especially over the 1980s tourism had easy finance from the state-controlled banking system and a great number of small and medium sized tourist enterprises were established, facilitated by the industrial policy (Law 1262/82) of granting investment incentives to private firms (Giannitsis 1993). In the current period about half of the hotel capacity in Greece belongs to small family units with up to 20 rooms each. ${ }^{4}$ Taking also into account that tourist services except accommodation are mainly provided by small family enterprises, it seems that the revenue from tourism activity is greatly spread to a large number of people.

\section{Analysis of data}

The empirical investigation of the long-run relationship between tourism and output is carried out using quarterly data for Greece over the period 1977Q1-2020Q2. The series of GDP per capita at 2015 prices is constructed using data obtained from the Hellenic Statistical Authority (ELSTAT) and EUROSTAT. For the indicator of tourism flow we employ data for the number of international tourist arrivals to Greece, obtained from ELSTAT and unpublished data provided by the Bank of Greece. Both series are seasonally adjusted using the U.S. Census Bureau's X12 seasonal adjustment program. The two variables are hereafter referred to as $Y$ for output and $T$ for tourism and their relationship is expected to be positive.

In the relevant empirical research, the volume of tourism flow is captured by certain variables. They include the number of tourist arrivals (Dritsakis 2004; Kim et al. 2006; Katircioglu 2009; Othman et al. 2012), tourist receipts (e.g. Balaguer

\footnotetext{
3 e.g. the Arab Spring; the civil war in Syria (2011); the crisis of Crimea and Ukraine (2014).

${ }^{4}$ For a discussion of recent developments and reforms in Greek tourism, see Bank of Greece (2019).
} 
Table 1 Conventional tests of normality

\begin{tabular}{llllll}
\hline & $\begin{array}{l}\text { Skewness/ } \\
\text { Kurtosis } \\
\text { (joint) }\end{array}$ & $J B$ & $S F$ & $S W$ & $K S$ \\
\hline $\ln Y$ & $18.550 * * *$ & $13.623 * * *$ & $4.872 * * *$ & $5.373 * * *$ & $0.1404 * * *$ \\
& $(0.000)$ & $(0.007)$ & $(0.000)$ & $(0.000)$ & $(0.002)$ \\
$\ln T$ & 1.270 & 1.0017 & $2.742 * * *$ & $2.840 * * *$ & 0.0619 \\
& $(0.5305)$ & $(0.564)$ & $(0.003)$ & $(0.002)$ & $(0.517)$ \\
\hline
\end{tabular}

$p$-values are in parentheses

$*$, ** denote significance at $10 \%$ and $5 \%$ level, respectively

and Cantavella-Jordá 2002; Aslan 2013; Ridderstaat et al. 2013), or tourist expenditures (Schubert et al. 2011; Cárdenas-García et al. 2015). However, all three variables are suitable for empirical research because there is a strong positive correlation among them, since high numbers of tourist arrivals are related to high tourist expenditures and high tourist receipts.

The statistical properties of the two series provide evidence of non-normal distribution, since GDP series exhibit positive skewness (Y: 0.731) and tourism series is highly skewed (T: 1.078). Also, the kurtosis statistic for output is lower than 3 (2.444, platykurtic distribution), while that for tourism is higher than 3 (3.608, leptokurtic distribution). The normality properties of the series are examined applying conventional and quantile mean covariance normality tests, such as Jarque-Berra (JB), Shapiro-Francia (SF), Shapiro-Wilk (SW), Kolmogorov-Smirnov (KS) and Joint Skewness and Kurtosis tests of normality. The test results (Table 1) provide strong evidence against normal distribution for both series. For the output series all tests reject normality, while for tourism series, SF and SW tests are in favour of the rejection of the null hypothesis.

Relying on a conventional test of normality, based on the conditional central tendency, could lead to erroneous conclusions that the behaviour of the series is uniform across the whole distribution. To investigate the existence of asymmetric distribution in the sampling performance of the two series the quantile-mean covariance (QC) test developed by Bera et al. (2016) is applied. This test is based on the quantile-mean covariance process, according to which the quantile-mean covariance function, $\mathrm{C}(\tau)$, is the asymptotic covariance between the sample quantiles with index $\tau \varepsilon(0,1)$ and the sample mean, namely

$$
C(\tau)=\lim _{n \rightarrow \infty} \sqrt{n} \operatorname{COV}\left(Y_{\tau, n}, \bar{X}_{n}\right),
$$

where $C(\tau)$ is the quantile-mean covariance (QC) function, $\left\{X_{1}, \ldots X_{n}\right\}$ is an i.i.d sample with distribution function $F(x)$, density $f(x)$, mean $\mu_{x}$ and quantile function $Q(\tau)$, where $0<\tau<1 . X_{n}$ denotes the sample mean and $Y_{\tau, n}$ denotes the sample $\tau$-th quantile, for which it holds that $\tau \mathrm{E}, T(\varepsilon, 1-\varepsilon), \varepsilon$ is a small positive number. Bera et al. (2016) have shown that the quantile-mean covariance (QC) function is constant and equal to the variance, if and only if the underlying 
Table 2 QC test of normality

\begin{tabular}{|c|c|c|c|c|c|c|}
\hline & \multicolumn{3}{|l|}{$\ln Y$} & \multicolumn{3}{|l|}{$\ln T$} \\
\hline & $T_{1 n}$ & $T_{2 n}$ & $T_{3 n}$ & $T_{1 n}$ & $T_{2 n}$ & $T_{3 n}$ \\
\hline \multirow{2}{*}{$\varepsilon=0.001$} & $1.998 * * *$ & $3.993 * * *$ & $0.602 * * *$ & $0.874^{*}$ & $0.765^{*}$ & $0.112 * *$ \\
\hline & $(0.000)$ & $(0.000)$ & $(0.000)$ & $(0.057)$ & $(0.057)$ & $(0.027)$ \\
\hline \multirow{2}{*}{$\varepsilon=0.01$} & $1.998 * * *$ & $3.993 * * *$ & $0.601 * * *$ & $0.874^{*}$ & $0.764^{*}$ & $0.112 * *$ \\
\hline & $(0.000)$ & $(0.000)$ & $(0.000)$ & $(0.057)$ & $(0.057)$ & $(0.027)$ \\
\hline \multirow[t]{2}{*}{$\varepsilon=0.05$} & $1.998 * * *$ & $3.993 * * *$ & $0.551 * * *$ & $0.874 * *$ & $0.764 * *$ & $0.095^{* *}$ \\
\hline & $(0.000)$ & $(0.000)$ & $(0.000)$ & $(0.041)$ & $(0.041)$ & $(0.032)$ \\
\hline \multirow[t]{2}{*}{$\varepsilon=0.10$} & $1.998 * * *$ & $3.994 * * *$ & $0.314 * * *$ & $0.874 * *$ & $0.764 * *$ & $0.071 * *$ \\
\hline & $(0.000)$ & $(0.000)$ & $(0.000)$ & $(0.017)$ & $(0.071)$ & $(0.044)$ \\
\hline \multirow[t]{2}{*}{$\varepsilon=0.15$} & $0.9253 * * *$ & $0.856 * * *$ & $0.163 * * *$ & $0.661 *$ & $0.437 *$ & 0.405 \\
\hline & $(0.002)$ & $(0.002)$ & $(0.000)$ & $(0.065)$ & $(0.065)$ & $(0.114)$ \\
\hline \multirow[t]{2}{*}{$\varepsilon=0.20$} & $0.825^{* * *} *$ & $0.683^{* * *}$ & $0.130 * * *$ & $0.617 * *$ & $0.381 * *$ & 0.026 \\
\hline & $(0.002)$ & $(0.002)$ & $(0.000)$ & (0.039) & (0.039) & $(0.161)$ \\
\hline
\end{tabular}

$p$-values are in parentheses

$*$, **, *** denote significance at $10 \%, 5 \%$ and $1 \%$ level, respectively

distribution is normal. For normality to be tested functionals of $\hat{C}_{n}(\tau)$ over $\tau$ E $T(\varepsilon, 1-\varepsilon)$ are considered using the following test statistics:

$$
T_{1 n}:=\sup _{\tau \mathrm{E} \mathrm{T}}\left|\hat{C_{n}}(\tau)\right|, T_{2 n}:=\sup _{\tau \mathrm{E} \mathrm{T}} \hat{C}_{n}(\tau)^{2}, T_{3 n}:=\int_{\tau \mathrm{E} \mathrm{T}} \hat{C}_{n}(\tau)^{2} d \tau
$$

The QC normality test has the advantage that the limiting distribution of the test is free of nuisance parameters and it takes into account the entire distribution instead of selected moments. Test-statistic values for $T_{1 n}, T_{2 n}, T_{3 n}$ and the corresponding $p$-values, with $\varepsilon=\{0.001,0.01,0.05,0.1,0.15,0.2\}$ as trimming parameters and approximate grid equal to 0.001 .

The results of the QC normality test (Table 2) indicate an asymmetric behaviour of both series distribution, as the null hypothesis of normality is rejected almost for all alternative values of the trimming parameter $\varepsilon$ and for alternative test statistics $\left(T_{1 n}, T_{2 n}, T_{3 n}\right)$, which is a strong sign of non-Gaussian features across the whole distribution of the two series.

These results strongly indicate that output and tourism are characterized by a non-normal distribution, a strong sign for the existence of nonlinearities. Therefore, we apply the BDS nonlinear dependence test (Brock et al. 1996) which tests the null hypothesis of i.i.d. assumption on the decentralized time series data. In case the null hypothesis is rejected, non-white linear and nonlinear dependence embedded in the series is possible. According to the results, the BDS statistic is significant for the majority of the dimensions (m) for both variables thus confirming the existence of nonlinearities (Table 3). 
Table 3 BDS test

\begin{tabular}{|c|c|c|c|c|c|}
\hline \multirow[t]{2}{*}{ Variable } & \multicolumn{5}{|l|}{ Raw series } \\
\hline & $\mathrm{m}=2$ & $\mathrm{~m}=3$ & $\mathrm{~m}=4$ & $\mathrm{~m}=5$ & $\mathrm{~m}=6$ \\
\hline $\ln Y$ & $\begin{array}{l}0.1895^{* * * *} \\
(44.600)\end{array}$ & $\begin{array}{l}0.3225^{* * * *} \\
(47.770)\end{array}$ & $\begin{array}{l}0.4124 * * * \\
(51.369)\end{array}$ & $\begin{array}{l}0.4718 * * * \\
(56.452)\end{array}$ & $\begin{array}{l}0.5104 * * * \\
(63.424)\end{array}$ \\
\hline $\ln T$ & $\begin{array}{l}0.1794 * * * \\
(42.631)\end{array}$ & $\begin{array}{l}0.3122^{* * * *} \\
(46.682)\end{array}$ & $\begin{array}{l}0.4041 * * * \\
(50.778)\end{array}$ & $\begin{array}{l}0.4687 * * * \\
(56.564)\end{array}$ & $\begin{array}{l}0.5135^{* * * *} \\
(64.319)\end{array}$ \\
\hline Variable & $\begin{array}{l}\text { Residuals serie } \\
\mathrm{m}=2\end{array}$ & $\begin{array}{l}\text { VAR model) } \\
\mathrm{m}=3\end{array}$ & $\mathrm{~m}=4$ & $\mathrm{~m}=5$ & $\mathrm{~m}=6$ \\
\hline $\ln Y$ & $\begin{array}{c}0.0094 \\
(1.418)\end{array}$ & $\begin{array}{c}0.0144 \\
(1.360)\end{array}$ & $\begin{array}{l}0.0170 \\
(1.341)\end{array}$ & $\begin{array}{l}0.0258^{*} \\
(1.940)\end{array}$ & $\begin{array}{l}0.0295 * * \\
(2.292)\end{array}$ \\
\hline $\ln T$ & $\begin{array}{l}-0.0116^{* * * *} \\
(-13.543)\end{array}$ & $\begin{array}{l}-0.0117 * * * \\
(-6.142)\end{array}$ & $\begin{array}{l}-0.0118 * * * \\
(-3.722)\end{array}$ & $\begin{array}{l}-0.0119 * * * \\
(-2.578)\end{array}$ & $\begin{array}{l}-0.0119^{* *} \\
(-1.931)\end{array}$ \\
\hline
\end{tabular}

The values represent the BDS statistic for the corresponding number of dimension (m)

$*, * *, * * *$ denote significance at $10 \%, 5 \%$ and $1 \%$ level. $z$ values are in parentheses

Overall, the results presented above provide evidence for significant nonlinearities and asymmetric distribution, with the non-Gaussian features arising mostly at the tails of the series.

\section{Econometric methodology}

To examine the relationship between output and tourism across the whole distribution and to allow for the possibility of the existence of asymmetric dynamics, we apply the following steps in our estimation procedure: First, we verify the order of integration of the variables by performing various conventional unit root tests. Second, having established that the variables are integrated of order one I(1), we investigate their long- and short-term interactions. We document the tourism-growth hypothesis by examining the presence of long-run cointegration between the variables, their causal equilibrium relationship and their short-run asymmetric adjustment process, by applying threshold cointegration estimation techniques (Threshold Autoregression Model (TAR) and Momentum Autoregression Model (MTAR), developed by Enders and Siklos (2001) and Sun (2011). Third, to consider the effects of changes of tourism on different quantiles of output, that is under various states of the economy, we utilize the QR analysis, following Koenker and Bassett (1978) and Nusair and Olson (2019). Finally, we implement asymmetric quantile analysis to examine the effects of positive and negative changes of tourism on output.

Quantile regression analysis provides a more comprehensive description of the conditional distribution than the ordinary mean approach and it offers a more robust econometric technique in the presence of conditional heterogeneity and departures from the Gaussian conditions. The quantile regression is formulated as follows. Let $\left\{y_{t}:=1, \ldots, T\right\}$ be a random sample on a random variable $Y$ having probability 
distribution function $F(y)=\operatorname{Prob}(Y \leq y)$, where the $\tau$-th quantile of $Y, 0<\tau<1$ is defined as the smallest $y$ satisfying $F(y) \geq \tau$, such that $Q(\tau)=\inf \left\{y_{t}: F(y) \geq \tau\right\}$.

Therefore, the $\tau$-th conditional quantile function of $y$ can be written as:

$$
Q_{y}(\tau / x)=\inf \left\{b / F_{y}(b / x) \geq \tau\right\}=\sum_{t}\left(a^{\tau}+x_{t} \beta^{\tau}\right)=a^{\tau}+x_{t}^{\prime} \beta^{\tau}
$$

Generally, conditional quantile model is specified in the following manner:

$$
Q_{y_{t}}(\tau / x)=a^{\tau}+x_{t}^{\prime} \beta^{\tau}
$$

where, $Q_{y_{t}}(\tau / x), 0<\tau<1$, is the conditional $\tau$-th quantile of the dependent variable, $y_{t}, x_{t}$ is a vector of independent variables, $\beta^{\tau}$ denotes the estimated coefficients and $a^{\tau}$ are the unobserved effects. The corresponding coefficients of the $\tau$-th quantile of the conditional distribution are given, equivalently, as the solution to the following minimization problem:

$$
\begin{aligned}
Q_{q_{t}}\left(\tau / x_{t}\right)= & \arg \min _{\hat{\beta} \varepsilon R^{k}}\left[\sum_{t: 1 y \geq a^{\tau}+x_{t}^{\prime} \hat{\beta}^{\tau}} \tau\left|y_{t}-a^{\tau}-x_{t}^{\prime} \beta^{\tau}\right|+\sum_{t: y<a^{\tau}+x_{t}^{\prime} \hat{\beta}^{\tau}}(1-\tau)\left|y_{t}-a^{\tau}-x_{t}^{\prime} \beta^{\tau}\right|+\right] \\
& =\arg \min _{\hat{\beta} \varepsilon R^{k}} \sum_{t} \rho_{\tau}\left(y_{t}-a^{\tau}-x_{t}^{\prime} \hat{\beta}^{\tau}\right)
\end{aligned}
$$

Equation (5) expresses the minimization of the weighted absolute deviations between the dependent and the explanatory variables, where $\rho_{\tau}$ is a weighted factor, the check function, which weighs positive and negative values asymmetrically and it is defined for $\tau=1 / 2 \varepsilon(0,1)$ as $\rho_{\tau}(z)=\tau z$, if $z \geq 0$ or $\rho_{\tau}(z)=(\tau-1) z$, if $z<0$, where $z_{t}=y_{t}-a^{\tau}-x_{t}^{\prime} \beta^{\tau}$. Consequently, the quantile regression methodology minimizes the sum of the residuals, where positive and negative residuals are weighted unequally, thus receiving a weight of $\tau$ and $1-\tau$, respectively. The regression quantile for $\tau=1 / 2$ corresponds to the least absolute error estimator, namely the regression median. The impact of the mean will represent the entire distribution only under the assumption that the marginal effects of the independent variable will be a simple location shift (Heckman et al. 1997). Otherwise, the coefficient $\beta^{\tau}$ represents the effects of the independent variable on the conditional $\tau$-th quantile of the conditional distribution.

Thus, to examine the effects of tourism on output we apply the quantile regression analysis as described in Eq. (6) below. In addition, to allow for the presence of asymmetry in the relationship between the two variables, tourism is decomposed into positive and negative changes and, next, the quantile regression analysis is applied, according to the model presented in Eq. (7) below. Both variables are expressed as first differences of their natural logarithms, namely $\Delta \ln Y=\ln Y_{t}-\ln Y_{t-1}$ and $\Delta \ln Y=\ln Y_{t}-\ln T_{t-1} \cdot Q_{\Delta \ln Y}\left(\tau / \Delta \ln T_{t}\right)$ denotes the conditional $\tau$-th quantile of the dependent variable $\Delta \ln Y, a^{\tau}$ is the intercept depending on the quantile, and $\beta^{\tau}$ is a vector of the coefficients to be estimated. $\Delta \ln T^{+}$with $\Delta \ln T^{+} \max (\Delta \ln T, 0)$ and $\Delta \ln T^{-}$with $\Delta \ln T^{-}=\min (\Delta \ln T, 0)$ denote positive and negative changes of the explanatory variable, namely the tourism series. 


$$
\begin{gathered}
Q_{\Delta \ln Y_{t}}\left(\tau / \Delta \ln T_{t}\right)=\alpha^{\tau}+\beta^{\tau} \Delta \ln T_{t} \\
Q_{\Delta \ln Y_{t}}\left(\tau / \Delta \ln T_{t}\right)=\alpha^{\tau}+\beta^{\tau+} \Delta \ln T_{t}^{+}+\beta^{\tau-} \Delta \ln T_{t}^{-}
\end{gathered}
$$

Following Nusair and Olson (2019) the quantiles are categorized into three regimes, corresponding to a bearish economy, where $\tau=(0.10,0.20,0.30)$; a normal economy, where $\tau=(0.40,0.50,0.60)$; and a flourishing economy, where $\tau=(0.70,0.80,0.90)$.

\section{Empirical results}

Initially, in Sect. 5.1, having verified that the two variables in consideration have the same order of integration, we examine whether they are characterized by a longrun equilibrium relationship, by applying the threshold autoregressive approach, developed by Enders and Siklos (2001). Then, following Sun (2011), we estimate an asymmetric error-correction model with threshold cointegration, which allows capturing asymmetries in the adjustment process and the causal relationships between the two variables. In Sect. 5.2 we apply QR analysis, following Koenker and Bassett (1978) and Nusair and Olson (2019), to examine the effects of changes of tourism on different quantiles of output, that is under various states of the economy.

\subsection{Threshold cointegration analysis}

\subsubsection{Unit root tests}

The first step is to verify the order of integration of the variables since the examination of long-run relationship among output and tourism, the presence of asymmetries and the relevant causality tests are valid only if the variables have the same order of integration. Conventional unit root tests are applied to test the stationary properties of the variables.

To this end, the stationarity properties of the variables are examined using the Augmented Dickey Fuller (ADF) and Kwiatkowski-Phillips-Schmidt-Shin (KPSS) test. For both tests we consider the case with intercept and the case with intercept and trend. The ADF tests the null hypothesis of a unit root and the KPSS tests the null hypothesis of stationarity. The results are reported in Table 4 (Part $A$ ). The ADF test statistics show that the null hypothesis of the unit root test for the level forms of the log transformed variables $(\ln Y, \ln T)$ cannot be rejected, but it is rejected for the first-order differences of the variables $(\Delta \ln Y, \Delta \ln T)$ at the $1 \%$ significance level. For the KPSS test the null hypothesis of stationarity is rejected but it cannot be rejected for the firstorder differences, revealing that both variables are integrated of order one I(1).

Moreover, we apply Zivot and Andrews (1992) unit root test and Lagrange Multiplier unit root test by Lee and Strazicich (2004) to account for possible structural breaks that indicate an asymmetric behaviour. The results are reported in Table 4 (Part B), showing that both variables are integrated of order one I(1). 
Table 4 Unit root tests

\begin{tabular}{|c|c|c|c|c|}
\hline & $\ln Y$ & $\Delta \ln Y$ & $\ln T$ & $\Delta \ln T$ \\
\hline \multicolumn{5}{|c|}{ Part A: Unit root test not allowing for structural breaks } \\
\hline $\mathrm{ADF}$ (intercept) & $-1.319[3]$ & $-4.201[2] * * *$ & $-2.010[0]$ & $-1.853[0]$ \\
\hline ADF (intercept \& trend) & $-0.273[3]$ & $-4.384[2] * * *$ & $-3.958[0] * * *$ & $-3.984[0] * *$ \\
\hline KPSS (intercept) & $2.988[3] * * *$ & $0.330[2]$ & $3.928[3] * * *$ & $0.294[3]$ \\
\hline KPSS (intercept \& trend) & $0.539[3] * * *$ & $0.109[3]$ & $0.129[1] *$ & $0.115[3]$ \\
\hline \multicolumn{5}{|c|}{ Part B: Unit root tests allowing for structural breaks } \\
\hline Zivot-Andrews ( 1 break) & $0.739[1]$ & $-5.331[2] * * *$ & $-1.295[0]$ & $4.637[0] * * *$ \\
\hline Breakpoint & 2010 Q1 & 2007 Q2 & 1989 Q3 & 2014 Q1 \\
\hline Lee and Strazicich (1 break) & $-2.506[3]$ & $-5.671[2] * * *$ & $-1.990[1]$ & $-5.642[1] * * *$ \\
\hline Breakpoint & 2005 Q2 & 2015 Q2 & 1992 Q1 & 2016 Q1 \\
\hline Lee and Strazicich ( 2 breaks) & $-3.756[3]$ & $-6.457[3] * * *$ & $-2.062[2]$ & $-5.896[3] * *$ \\
\hline \multirow[t]{2}{*}{ Breakpoints } & 1993 Q4 & 2008 Q1 & 1987 Q1 & 1986 Q4 \\
\hline & 2006 Q1 & 2015 Q2 & 1992 Q1 & 2016 Q2 \\
\hline
\end{tabular}

In brackets is the number of lags used in the test; the lag order is in accordance with the Akaike Information Criterion (AIC)

$*, * *, * * *$ denote significance at $10 \%, 5 \%$ and $1 \%$ level

Overall, the results from all tests confirm that the two variables are integrated of order one, which implies that cointegration test can be used to search for the existence of a long-run equilibrium relationship between the two series.

\subsubsection{Long-run equilibrium model}

Having established that the variables are integrated of order one I(1), we investigate their long- and short-term interactions. To examine the existence of nonparametric effects and the presence of a causal equilibrium relationship between the variables, we apply threshold cointegration estimation techniques (TAR and MTAR model estimation) by Enders and Siklos (2001) and Sun (2011). The TAR model captures deep movements in the residuals, while the MTAR deals with steep variations in the residuals.

We proceed by establishing a long-term equilibrium relationship between the two variables, as follows:

$$
\ln Y_{t}=a_{0}+\alpha_{1} \ln T_{t}+\varepsilon_{t}
$$

where $a_{i}$ are the coefficients of the relationship and $\varepsilon_{t}$ is the error term. The empirical results (Table 5) show that tourism has a statistically significant positive effect on output in the long term. The elasticity of output with respect to tourism is 0.214 , implying that a 10 percent increase in tourist arrivals is associated with an increase of 2.14 percentage points in output. 
Table 5 Long-run (cointegrating) relationship Dependent variable: $\ln Y$

\begin{tabular}{lcc}
\hline Variable & estimate & t-statistic \\
\hline $\ln T$ & $0.214^{* * *}$ & 13.021 \\
intercept & $-0.325^{* *}$ & -2.481 \\
$\mathrm{R}^{2}$ - adj & 0.4949 & \\
S.E of Regression & 0.1101 & \\
F-statistic & 169.5 & \\
\hline
\end{tabular}

*** denotes significance level at $1 \%$ level

To examine whether the relationship between tourism and output adjusts towards the estimated long-run equilibrium model, a two-regime threshold model is applied that allows for possible asymmetric cointegrating effects, as follows:

$$
\begin{gathered}
\Delta \hat{\varepsilon}_{t}=\rho_{1} I_{t} \hat{\varepsilon}_{t-1}+\rho_{2}\left(1-I_{t}\right) \hat{\varepsilon}_{t-1}+\sum_{i=1}^{p} \varphi_{i} \Delta \hat{\varepsilon}_{t-1}+\mu_{t} \\
I_{t}=1, \hat{\varepsilon}_{t-1} \geq \tau, 0 \text { otherwise } \\
I_{t}=1, \Delta \hat{\varepsilon}_{t-1} \geq \tau, 0 \text { otherwise }
\end{gathered}
$$

where, $\hat{\varepsilon}_{t}$ are the estimated residuals from the long-run equilibrium relationship, $\rho_{1}, \rho_{2}, \varphi_{1}$ are coefficients to be estimated, $p$ is the number of lags, $\mu_{t} \approx \operatorname{iid}\left(0, \sigma_{\varepsilon}^{2}\right)$. The lag selection of $p$ is specified using AIC and BIC values. $I_{t}$ is the Heaviside indicator, where $\tau$ is the value of threshold, which can be endogenously determined using Chan's (1993) methodology The Heaviside indicator can be specified with two different definitions of the threshold variable $(\tau)$, defining the TAR model (Eq. 10) and the MTAR model (Eq. 11). ${ }^{5}$

Following Sun (2011), the four threshold cointegration models presented in Table 6 are specified as follows: (a) TAR where in Eq. (10) $\tau=0$, (b) consistent TAR where in Eq. (10) $\tau$ is estimated using Chan's (1993) methodology, (c) MTAR where in Eq. (11) $\tau=0$ and (d) consistent MTAR where in Eq. (11) $\tau=0$ is estimated using Chan's (1993) methodology. To select the appropriate number of lags for each of the four models, initially a maximum of four lags is specified. Then diagnostic analysis on the residuals using the AIC statistics is applied. The lag specifications with the lowest AIC value are selected. In the cases of the TAR, consistent TAR and MTAR models three lags provide the lowest AIC value, while for the case of the consistent MTAT model, one lag provides the lowest value of the statistic.

\footnotetext{
5 Acçording to this method the values of the estimated residual series, $\hat{\varepsilon}_{t-1}$ for the case of the TAR model and $\Delta \varepsilon_{t-1}$ for the case of the MTAR model are sorted in ascending order and the largest and smallest $15 \%$ of the values are discarded. The remaining $70 \%$ of the values are possible thresholds and the estimated threshold yielding the lowest residual sum of squares is the consistent estimate of the threshold parameter. Alternatively, the threshold value $\tau$ can be set equal to zero.
} 
Table 6 Results of threshold cointegration estimations

\begin{tabular}{|c|c|c|c|c|}
\hline Estimate & TAR & Consistent TAR & MTAR & Consistent MTAR \\
\hline Threshold & 0.000 & -0.063 & 0.000 & -0.021 \\
\hline$\rho_{1}$ & $\begin{array}{l}-0.012 \\
(0.514)\end{array}$ & $\begin{array}{l}-0.004 \\
(0.832)\end{array}$ & $\begin{array}{c}0.001 \\
(0.994)\end{array}$ & $\begin{array}{c}0.004 \\
(0.785)\end{array}$ \\
\hline$\rho_{2}$ & $\begin{array}{l}-0.018 \\
(0.484)\end{array}$ & $\begin{array}{l}-0.038 \\
(0.160)\end{array}$ & $\begin{array}{l}-0.025 \\
(0.206)\end{array}$ & $\begin{array}{l}-0.097 * * * \\
(0.010)\end{array}$ \\
\hline$\varphi_{1}$ & $\begin{array}{l}-0.173 * * \\
(0.028)\end{array}$ & $\begin{array}{l}-0.165 * * \\
(0.036)\end{array}$ & $\begin{array}{l}-0.177 * * \\
(0.024)\end{array}$ & $\begin{array}{l}-0.166^{* *} \\
(0.025)\end{array}$ \\
\hline$\varphi_{2}$ & $\begin{array}{c}0.037 \\
(0.641)\end{array}$ & $\begin{array}{c}0.042 \\
(0.600)\end{array}$ & $\begin{array}{c}0.033 \\
(0.676)\end{array}$ & - \\
\hline$\varphi_{3}$ & $\begin{array}{l}0.154 * * \\
(0.049)\end{array}$ & $\begin{array}{l}0.156^{* * *} \\
(0.045)\end{array}$ & $\begin{array}{l}0.154 * * \\
(0.048)\end{array}$ & - \\
\hline \multicolumn{5}{|l|}{ Diagnostics } \\
\hline AIC & -818.308 & -819.457 & -819.035 & -836.365 \\
\hline $\mathrm{BIC}$ & -799.528 & -800.678 & -800.255 & -823.798 \\
\hline \multicolumn{5}{|l|}{ Hypotheses } \\
\hline $\begin{array}{c}\Phi\left(H_{0}: \rho_{1}=\rho_{2}=0\right) \\
\text { No cointegration }\end{array}$ & $\begin{array}{c}0.452 \\
(0.637)\end{array}$ & $\begin{array}{l}1.015 \\
(0.365)\end{array}$ & $\begin{array}{c}0.808 \\
(0.448)\end{array}$ & $\begin{array}{l}3.457 * * \\
(0.034)\end{array}$ \\
\hline $\begin{array}{l}F\left(H_{0}: \rho_{1}=\rho_{2}\right) \\
\quad \text { Symmetry }\end{array}$ & $\begin{array}{c}0.038 \\
(0.845)\end{array}$ & $\begin{array}{l}1.158 \\
(0.284)\end{array}$ & $\begin{array}{c}0.746 \\
(0.389)\end{array}$ & $\begin{array}{l}6.358^{* *} \\
(0.013)\end{array}$ \\
\hline
\end{tabular}

$p$-values are in parentheses

$*, * *, * * *$ denote significance at $10 \%, 5 \%$ and $1 \%$ level respectively

The consistent MTAR model has the lowest AIC (-836.365) and BIC $(-823.798)$ statistics and it is chosen as the best model for the development of the error-correction model (ECM) estimation.

The $\Phi$-statistic $\left(\mathrm{H}_{0}: \rho_{1}=\rho_{2}=0\right)$ for the consistent MTAR model has a value of 3.457 , which is statistically significant. Therefore, the null hypothesis of no threshold cointegration is rejected and the level of output and the level of tourism are cointegrated. Also, the $F$-statistic $\left(\mathrm{H}_{0}: \rho_{1}=\rho_{2}\right)$ of the MTAR model has a value of 6.358 which is also statistically significant. Therefore, the null hypothesis of symmetric adjustment is rejected and when the level of output and tourism are adjusting towards the long-run equilibrium, the adjustment process is asymmetric, implying a threshold cointegration. In particular, the point estimate for the adjustment process for positive shocks is 0.004 , statistically insignificant, which is above threshold deviations from long-run equilib$\operatorname{rium}\left(\Delta \varepsilon_{t-1} \geq-0.021\right)$. For negative shocks it is -0.097 , which is below threshold deviations from long-run equilibrium $\left(\Delta \varepsilon_{t-1}<-0.021\right)$. Consequently, the threshold cointegration analysis reveals that the long-term relationship between tourism and output is characterized by a substantially faster convergence of output after a negative shock, than after a positive one. This indicates that tourism contributes to a faster absorption of a negative exogenous shock in output compared to a positive one. 


\subsubsection{Short-run asymmetric dynamics error-correction model with threshold cointegration}

To examine the short-run dynamics of the tourism-output relationship we follow Sun (2011). This process allows examining how the two variables interact with each other through an adjustment process to a new target level when a positive or negative exogenous shock, occurs. Given that the consistent MTAR model is preferable to other models, we construct the error-correction terms using Eqs. (9) and (11). A lag of one is selected for the models based on the AIC statistics. We proceed by estimating the two asymmetric error-correction models with threshold cointegration as in Eqs. (12) and (13):

$$
\begin{aligned}
\Delta \ln Y_{t} & =\theta_{\ln Y}+\delta_{\ln Y}^{+} E_{t-1}^{+}+\delta_{\ln Y}^{-} E_{t-1}^{-}+\sum_{j=1}^{J} a_{\ln Y_{j}}^{+} \ln Y_{t-j}^{+}+\sum_{j=1}^{J} a_{\ln Y_{j}} \ln Y_{t-j}^{-} \\
& +\sum_{j=1}^{J} \beta_{\ln Y j}^{+} \ln T_{t-j}^{+}+\sum_{j=1}^{J} \beta_{\ln Y j}^{-} \ln T_{t-j}^{-}+u_{\ln Y t} \\
\Delta \ln T_{t} & =\theta_{\ln T}+\delta_{\ln T}^{+} E_{t-1}^{+}+\delta_{\ln T}^{-} E_{t-1}^{-}+\sum_{j=1}^{J} a_{\ln T_{j}}^{+} \ln Y_{t-j}^{+}+\sum_{j=1}^{J} a_{\ln T_{j}}^{-} \ln Y_{t-j}^{-} \\
& +\sum_{j=1}^{J} \beta_{\ln T j}^{+} \ln T_{t-j}^{+}+\sum_{j=1}^{J} \beta_{\ln T j}^{-} \ln T_{t-j}^{-}+u_{\ln T t}
\end{aligned}
$$

where $\theta$ is a constant, $a_{j}, \beta_{j}$ are the coefficients of the lagged first differences, $j$ represents the number of lags, which is chosen taking into account the AIC and BIC statistics, ensuring that the residuals have no serial correlation, $u$ is the error term and $E$ are the error-correction terms. $E_{t-1}^{+}=I_{t} \varepsilon_{t-1}^{\wedge}$ and $E_{t-1}^{-}=\left(1-I_{t}\right) \varepsilon_{t-1}^{\wedge}$ are constructed from the threshold cointegration regressions in Eqs. (9) and (11) and account for the asymmetric level of tourism and output in response to positive and negative shocks to the deviations from long-run equilibrium and also consider the impact of threshold cointegration through the construction of Heaviside indicator in Eqs. (9) and (11). The lagged variables in first difference $\Delta \ln Y_{t-j}$, $\Delta \ln T_{t-j}$ are split into positive $\left(\Delta \ln Y_{t-j}^{+}, \Delta \ln T_{t-j}^{+}\right)$and negative components $\left(\Delta \ln Y_{t-j}^{-}, \Delta \ln T_{t-j}^{-}\right)$. The results of the asymmetric error-correction models are reported in Table 7.

The point estimates of the ECM's coefficients for output growth are -0.004 and -0.068 for positive and negative shocks respectively. Output adjustment to long-run equilibrium due to positive shocks fade out at a quarterly rate of $0.04 \%$, while negative deviations at a quarterly rate of $6.8 \%$. Therefore, in the short-run, output has a substantially faster responding speed for negative deviations. Furthermore, the ECM's coefficients for positive shocks are statistically insignificant and for negative shocks are significant at 5\% level of confidence. This evidence suggests that in the short-term the adjustment path occurs through the level of output for negative 
Table 7 Results of the asymmetric error-correction model with threshold cointegration

\begin{tabular}{|c|c|c|c|c|}
\hline \multirow[t]{2}{*}{ Estimate } & \multicolumn{2}{|l|}{$\Delta \ln Y$} & \multicolumn{2}{|l|}{$\Delta \ln T$} \\
\hline & estimate & t-ratio & estimate & t-ratio \\
\hline$\theta$ & $\begin{array}{c}0.001 \\
(0.607)\end{array}$ & 0.026 & $\begin{array}{c}0.003 \\
(0.797)\end{array}$ & 0.257 \\
\hline$\delta^{+}$ & $\begin{array}{l}-0.004 \\
(0.742)\end{array}$ & -0.329 & $\begin{array}{l}-0.038 \\
(0.481\end{array}$ & -0.706 \\
\hline$\delta^{-}$ & $\begin{array}{l}-0.068^{* *} \\
(0.023\end{array}$ & -2.294 & $\begin{array}{r}0.087 \\
(0.508\end{array}$ & 0.664 \\
\hline$\alpha_{1}^{+}$ & $\begin{array}{r}0.766 \\
(0.271\end{array}$ & 1.104 & $\begin{array}{r}0.143 \\
(0.363\end{array}$ & 0.912 \\
\hline$\alpha_{1}^{-}$ & $\begin{array}{l}-0.268 \\
(0.647\end{array}$ & -0.459 & $\begin{array}{r}0.036 \\
(0.788\end{array}$ & 0.269 \\
\hline$\beta_{1}^{+}$ & $\begin{array}{l}-0.227^{*} \\
(0.075\end{array}$ & -1.794 & $\begin{array}{r}0.001 \\
(0.979\end{array}$ & 0.026 \\
\hline$\beta_{1}^{-}$ & $\begin{array}{l}-0.439 * * * \\
(0.001\end{array}$ & -3.233 & $\begin{array}{c}0.024 \\
(0.432)\end{array}$ & 0.787 \\
\hline \multicolumn{5}{|l|}{ Diagnostics } \\
\hline AIC & -922.969 & & -415.103 & \\
\hline BIC & -897.836 & & -389.970 & \\
\hline \multicolumn{5}{|l|}{ Hypotheses } \\
\hline$F\left(H_{0}: \delta^{+}=\delta^{-}\right)$ & $4.064 * *$ & & 0.788 & \\
\hline Symmetry & $(0.045)$ & & $(0.376)$ & \\
\hline$F\left(H_{0}: a_{i}^{+}=a_{i}^{-}=0\right)$ & 0.610 & & 0.675 & \\
\hline Asymmetric Granger Causality & $(0.545)$ & & $(0.510)$ & \\
\hline$F\left(H_{0}: \beta_{i}^{+}=\beta_{i}^{-}=0\right)$ & $9.968 * * *$ & & 0.359 & \\
\hline Asymmetric Granger Causality & $(0.000)$ & & $(0.699)$ & \\
\hline
\end{tabular}

$p$-values are in parentheses

$*, * *, * * *$ denote significance at $10 \%, 5 \%$ and $1 \%$ level respectively

deviations from long-run equilibrium. Consequently, as the adjustment process is performed through the modification of output, the driving force (exogenous) variable is tourism. In addition, there is not short-term momentum equilibrium adjustment path in the tourism ECM as the point estimates of the ECM's coefficients for tourism growth for positive and negative shocks are not statistically significant.

The same conclusion is obtained by examining the distributed lag effects. At the first lag, the coefficients of tourism for positive and negative changes are statistically significant, however the coefficient for negative deviations (-0.439) is higher than the corresponding coefficient for positive deviations (-0.227), thus indicating an asymmetric distributed lag effect. Specifically, the impact of tourism is stronger in the case of negative shocks on output in comparison to positive shocks. Furthermore, none of the distributed lag coefficients of output affects tourism growth. As a result, tourism is confirmed to be the driving force, namely the exogenous variable (causality effect). 
To confirm the direction of the causality effect, we follow Sun (2011) by applying Granger Causality tests for both equations and both variables, namely $F\left(H_{0}: a_{i}^{+}=a_{i}^{-}=0\right)$ and $F\left(H_{0}: \beta_{i}^{+}=\beta_{i}^{-}=0\right)$. According to our results, the F-statistic of 9.968 and the $p$-value (0.000) reveal that the lagged value of tourism does Granger cause the level of output, while the F-statistic of 0.675 and the $p$-value 0.510 reveal the lagged value of output does not Granger cause the level of tourism. These results provide strong evidence in favor of an asymmetric causality between the two variables and they also confirm that the tourism variable is the driving force (exogenous variable) and thus, the adjustment process takes place though the level of output.

Furthermore, the lower values of the AIC and BIC statistics for the output equation compared to that of tourism suggest that the model specification has a better fit on the output ECM than on tourism and the adjustment process takes place through output. Thus, the only causality channel is through output, whereas tourism is evolving more independently, representing the exogenous variable.

Overall, our results provide evidence in favour of both an asymmetric and a causality effect. Firstly, we document asymmetric effect behaviour both in the short and long term, as there is a substantial faster and statistically significant speed of adjustment of output in the case of negative shocks compared to positive ones. In fact, there is not a statistically significant adjustment process for output when a positive shock occurs. Secondly, the threshold error-correction model analysis reveals that the short-run equilibrium adjustment process occurs through the output variable, while the tourism variable is the driving force (exogenous variable). These findings combined together add to the existing literature in that tourism leads to a faster absorption of a negative exogenous shock in output, in comparison to a positive shock. This evidence reveals that tourism contributes to a faster output adjustment after a negative shock, thus restricting the intense output fall and contributing to a more rapid absorption of negative shock effects.

\subsection{Quantile regression analysis}

As presented above, there is ample evidence that $\mathrm{QR}$ analysis would allow effects of the covariates to differ across conditional quantiles and in particular examine the tourism-led growth hypothesis at different points in the conditional distribution of output, that is in the case of a bearish (lower quantile), flourishing (upper quantile) or normal (intermediate quantile) economy.

Table 8 presents the results from the linear quantile regression model as shown in Eq. (6). Following Nusair and Olson (2019) the quantiles are categorized into three regimes, that is a bearish economy $[\tau=(0.10,0.20,0.30)]$, a normal economy $[\tau=(0.40,0.50,0.60)]$ and a flourishing economy $[\tau=(0.70,0.80,0.90)]$. The results provide evidence in favour of the existence of a positive dependence path between the two variables for the quantiles $[\tau=(0.10,0.20, \ldots, 0.60)]$, where the impact of tourism is statistically significant. In addition, besides a strong degree of path dependency, the findings indicate that at the lower part of the conditional distribution of output the effect of tourism becomes stronger, while at the upper part of the 
Table 8 Estimation results for the linear quantile model

\begin{tabular}{|c|c|c|c|c|c|}
\hline & \multirow[b]{2}{*}{ Quantile } & \multicolumn{2}{|l|}{$\Delta \ln T$} & \multicolumn{2}{|l|}{ Constant } \\
\hline & & Estimate & $\mathrm{t}$-statistic & Estimate & t-statistic \\
\hline \multirow[t]{3}{*}{ Bearish economy } & $\mathcal{Q}_{0.1}$ & $0.04554 * * *$ & 9.30378 & $0.00474 * * *$ & 2.74441 \\
\hline & $\mathcal{Q}_{0.2}$ & $0.04477 * * *$ & 8.74761 & 0.00249 & 1.39356 \\
\hline & $\mathcal{Q}_{0.3}$ & $0.04227 * * *$ & 9.69914 & $-0.00478 * * *$ & -2.69216 \\
\hline \multirow[t]{3}{*}{ Normal economy } & $\mathcal{Q}_{0.4}$ & $0.04393 * * *$ & 8.95317 & 0.00005 & 0.02858 \\
\hline & $\mathcal{Q}_{0.5}$ & $0.04062 * * *$ & 10.65697 & $-0.00957 * * *$ & -5.20484 \\
\hline & $\mathcal{Q}_{0.6}$ & $0.03728 * * *$ & 12.23800 & $-0.01927 * * *$ & -8.31689 \\
\hline \multirow[t]{3}{*}{ Flourishing economy } & $\mathcal{Q}_{0.7}$ & 0.03858 & 1.35231 & $0.00942 * * *$ & 5.40006 \\
\hline & $\mathcal{Q}_{0.8}$ & 0.03813 & 0.67668 & $0.01438 * * *$ & 8.22355 \\
\hline & $\mathcal{Q}_{0.9}$ & 0.03151 & 0.40759 & $0.01968 * * *$ & 11.72686 \\
\hline
\end{tabular}

$*, * *, * * *$ denote significance at $10 \%, 5 \%$ and $1 \%$ level respectively

conditional distribution the effect of tourism becomes weaker and statistically insignificant. Specifically, in the case of a flourishing economy, the corresponding quantile coefficients are $Q_{\Delta \ln Y}=(0.0385,0.0381,0.0315)$ with the highest impact being equal to 0.0385 observed for $\tau=0.70$. When the economy is at a normal state, the estimated quantile coefficients are $Q_{\Delta l n Y}=(0.0439,0.0406,0.0372)$, with the highest impact being equal to 0.0439 , for $\tau=0.40$. In the lower tail of the distribution corresponding to a bearish economy, the estimated coefficients are $Q_{\Delta \ln Y}=(0.0455,0.0447,0.0422)$ and the strongest impact is estimated 0.0455 for $r=0.10$. Overall, our results indicate that although the impact of tourism remains positive over the whole distribution, the magnitude of the effect is more intense at the lower quantiles of the output distribution.

To further examine the existence of asymmetries in the tourism-output relationship, we decompose the tourism growth variable into positive, $\Delta \ln T^{+}$ with $\Delta \ln T^{+}=\max (\Delta \ln T, 0) \quad$ and negative components, $\Delta \ln T^{-} \quad$ with $\Delta \ln T^{-}=\min (\Delta \ln T, 0)$. The results reported in Table 9 indicate that in the case of positive changes of the explanatory variable the sign of the impact remains positive and statistically significant over the whole distribution of output growth. However, the magnitude of the positive impact, as in the case of the linear quantile model, is more intense at the lower (bearish economy) relative to the higher quantiles (flourishing economy). On the contrary, the results reported for the negative impact of tourism provide a different picture to the case of the positive ones. Negative changes of the tourism variable are significantly related to declining output growth only at the higher quantile $(\tau=0.90)$. Overall, the declining impact of positive tourism changes at the upper quantiles of the output distribution for the asymmetric quantile model and the declining but statistically insignificant coefficients, at the upper quantiles of the output distribution of the linear model, may suggest that for higher output growth the economy is not dependent on positive shocks in the tourism industry. The economy needs to rely on other than tourism shocks to achieve higher economic growth rates. This finding suggests that the policymakers should put emphasis on policies that enhance economic growth, such as the implementation of structural reforms, the creation of a business-friendly environment to attract foreign investment, the promotion of advances in technology and the investment in human capital. 
Table 9 Estimation results for the asymmetric quantile model

\begin{tabular}{|c|c|c|c|c|c|c|c|}
\hline & \multirow[b]{2}{*}{ Quantile } & \multicolumn{2}{|l|}{$\Delta \ln T^{+}$} & \multicolumn{2}{|l|}{$\Delta \ln T^{-}$} & \multicolumn{2}{|l|}{ Constant } \\
\hline & & Estimate & t-statistic & Estimate & t-statstic & Estimate & t-tatistic \\
\hline \multirow[t]{3}{*}{ Bearish economy } & $\mathcal{Q}_{0.1}$ & $0.05130 * * *$ & 17.54111 & 0.00582 & 0.15805 & $0.02148 * * *$ & 10.69820 \\
\hline & $\mathcal{Q}_{0.2}$ & $0.04934 * * *$ & 12.97771 & -0.02088 & -0.70147 & $0.01578 * * *$ & 7.87564 \\
\hline & $\mathcal{Q}_{0.3}$ & $0.04819 * * *$ & 10.67092 & -0.02397 & -0.76250 & $0.01243 * * *$ & 5.85549 \\
\hline \multirow[t]{3}{*}{ Normal economy } & $\mathcal{Q}_{0.4}$ & $0.04619 * * *$ & 9.03524 & 0.00907 & 0.26211 & $0.00662 * * *$ & 3.00379 \\
\hline & $\mathcal{Q}_{0.5}$ & $0.04508^{* * * *}$ & 8.16887 & 0.01691 & 0.46815 & 0.00340 & 1.47298 \\
\hline & $\mathcal{Q}_{0.6}$ & $0.04424 * * *$ & 8.27990 & 0.02061 & 0.58356 & 0.00094 & 0.40941 \\
\hline \multirow{3}{*}{$\begin{array}{c}\text { Flourishing } \\
\text { economy }\end{array}$} & $\mathcal{Q}_{0.7}$ & $0.04227 * * *$ & 9.44439 & 0.03926 & 0.24044 & $-0.00478 * *$ & 0.03859 \\
\hline & $\mathcal{Q}_{0.8}$ & $0.04086^{* * *}$ & 10.34322 & 0.02314 & 0.69281 & $-0.00887 * * *$ & 0.00016 \\
\hline & $\mathcal{Q}_{0.9}$ & $0.03713 * * *$ & 12.17880 & $0.06119 *$ & 1.83195 & $-0.01971 * * *$ & -6.92660 \\
\hline
\end{tabular}

$*, * *, * * *$ denote significance at $10 \%, 5 \%$ and $1 \%$ level respectively

Overall, our results from the linear and the asymmetric QR analysis suggest that tourism growth exhibits asymmetric impact on output growth. Namely, the impact of tourism is more intense at the lower quantiles of the output distribution (bearish economy) relative to the higher quantiles (flourishing economy) where its impact is milder. The results show that tourism contributes to the greatest extent in the case of bearish, low income, economy or, after a negative shock, thus restricting the intensity of the output fall.

\section{Robustness analysis}

Having validated that the tourism-output relationship exhibits asymmetric behaviour, and particularly that a more intense impact of tourism prevails at lower quantiles of the output distribution, a robustness analysis of this findings is performed. An alternative Quantile-on-Quantile (QQ) model methodology, developed by Sim and Zhou (2015) is introduced. This QQ approach contains more disaggregated information about the tourism-output linkages as the relationship is perceived as potentially heterogeneous across different quantiles of the conditional distribution (Shahzad et al. 2017; Shahbaz et al. 2018). Consequently, it allows estimating the relationship between various quantiles of the independent and dependent variables, thus providing more detailed information than a conventional or even an asymmetric quantile regression.

Following Zhou and Sim (2015) the following nonparametric quantile regression equation is established:

$$
\Delta \ln Y_{t}=a^{\theta} \Delta \ln T_{t}+u_{t}^{\theta}
$$

where $\theta$ is the $\theta$ th quantile of the conditional distribution of output, $u_{t}^{\theta}$ denotes the quantile residuals. $\alpha^{\theta}(\cdot)$ is an unknown function, called link function, which we allow to be unknown, given that we lack prior information on the relationship between the two variables we study. 
To determine the relationship between the $\theta-$ th quantile of output-growth and the $\tau-t$ th quantile of tourism growth, $\Delta \ln T^{\tau}$, Eq. (14) in the neighbourhood of $\Delta \ln T^{\tau}$ is examined. Thus, we linearize and take a first order expansion around a quantile of $\Delta \ln T^{\tau}$, given that $\alpha^{\theta}(\cdot)$ is an unknown function. Consequently, the regression function is transformed in the following form:

$$
a^{\theta}\left(\Delta \ln T_{t}\right) \approx a^{\theta}\left(\Delta \ln T^{\tau}\right)+a^{\theta^{\prime}}\left(\Delta \ln T^{\tau}\right)\left(\Delta \ln T_{t}-\Delta \ln T^{\tau}\right)
$$

where $a^{\theta^{\prime}}$ is the partial derivative of $a^{\theta}\left(\Delta \ln T_{t}\right)$ with respect to $\Delta \ln T$. An important aspect of Eq. (15) is that the parameters $a^{\theta}\left(\Delta \ln T^{\tau}\right)$ and $a^{\theta^{\prime}}\left(\Delta \ln T^{\tau}\right)$ are dual indexed in $\theta$ and $\tau$. Therefore, the parameters $a^{\theta}\left(\Delta \ln T^{\tau}\right)$ and $a^{\theta^{\prime}}\left(\Delta \ln T^{\tau}\right)$ are described as $\alpha_{0}(\theta, \tau)$ and $\alpha_{1}(\theta, \tau)$. Accordingly, Eq. (15) becomes:

$$
a^{\theta}\left(\Delta \ln T_{t}\right) \approx a_{0}(\theta, \tau)+a_{1}(\theta, \tau)\left(\Delta \ln T_{t}-\Delta \ln T^{\tau}\right)
$$

Substituting Eq. (16) into Eq. (14) we obtain:

$$
\Delta \ln Y_{t}=a_{0}(\theta, \tau)+a_{1}(\theta, \tau)\left(\Delta \ln T_{t}-\Delta \ln T^{\tau}\right)_{t}+u_{t}^{\theta}
$$

Equation (17) captures the relationship between the $\theta-$ th quantile of output growth $(\Delta \ln Y)$ and the $\tau-t$ th quantile of tourism growth $(\Delta \ln T)$ through the dependence of their distributions, given the parameters $a_{0}$ and $a_{1}$ are doubly indexed in $\theta$ and $\tau$. The estimates $\hat{a}_{0}(\theta, \tau), \hat{a}_{1}(\theta, \tau)$ are obtained by solving the following minimization problem:

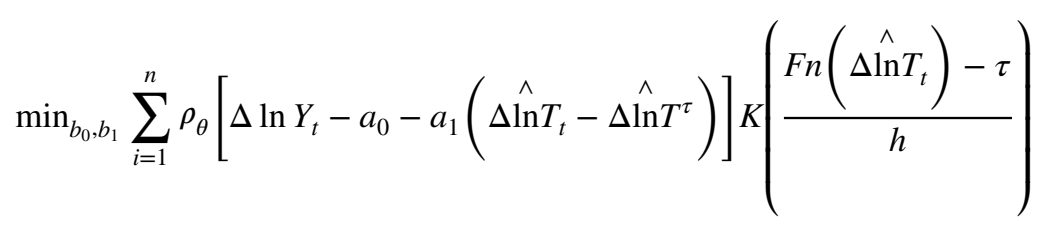

where $\rho_{\theta}(u)$ is the quantile loss function $\rho_{\theta}(u)=u(\theta-l(u<0))$ that gives as a solution the $\theta-t h$ conditional quantile of $Y_{t}, I$ is an indicator function, $K(\bullet)$ is a Gaussian kernel function that weights the observations in the neighbourhood of $\Delta \hat{\ln T^{\tau}}$ and $h$ denotes the bandwidth parameter of the kernel function. The weights of the observations are inversely related to the distance of the distribution function

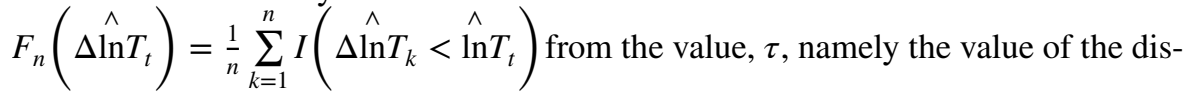
tribution function corresponding to $T^{\tau}$.

Table 10 presents the QQ approach estimation results of the slope coefficient $\alpha_{1}(\theta, \tau)$, regressing $\theta$-quantile, $\theta=(0.05,0.10,0.25,0.75,0.90,0.95)$ of output on the $\tau$-quantile, $\tau=(0.05,0.10,0.25,0.75,0.90,0.95)$ of tourism. The results show that the relationship between the two variables exhibits asymmetric behaviour and that the cumulative impact of tourism quantiles on the $\theta-t$ conditional quantile of output is more pronounced at the lower quantiles of the conditional output distribution, in line with the finding of Shahzad et al. (2017) for France and Italy. Overall, 
Table 10 Estimation results for the quantile on quantile (QQ) approach

\begin{tabular}{|c|c|c|c|c|c|c|c|}
\hline \multirow[b]{2}{*}{$\begin{array}{l}\text { Quantile of } \Delta \\
\ln T(\tau)\end{array}$} & \multicolumn{7}{|c|}{ Quantile of $\Delta \ln Y(\theta)$} \\
\hline & $\mathcal{Q}_{0.05}$ & $\mathcal{Q}_{0.05}$ & $\mathcal{Q}_{0.25}$ & $\mathcal{Q}_{0.5}$ & $\mathcal{Q}_{0.75}$ & $\mathcal{Q}_{0.90}$ & $\mathcal{Q}_{0.95}$ \\
\hline $\mathcal{Q}_{0.05}$ & $0.1296^{* * * *}$ & $0.0675^{* *}$ & $0.1321 * *$ & $0.1328 * * *$ & $0.1157 * *$ & $0.1044 * * *$ & $0.0882 * * *$ \\
\hline $\mathcal{Q}_{0.10}$ & $0.1383 * * *$ & $0.3603 * * *$ & $0.2659 * * *$ & $0.1734 * * *$ & $0.1334 * * *$ & $0.1173 * * *$ & $0.1002 * * *$ \\
\hline $\mathcal{Q}_{0.25}$ & $0.3873 * * *$ & $0.3773 * * *$ & $0.3118 * * *$ & $0.2002 * * *$ & $0.1519 * * *$ & $0.1404 * * *$ & $0.1175^{* * *} *$ \\
\hline $\mathcal{Q}_{0.5}$ & $0.3901 * * *$ & $0.3904 * * *$ & $0.3354 * * *$ & $0.2151 * * *$ & $0.1586 * * *$ & $0.1625 * * *$ & $0.1651 * * *$ \\
\hline $\mathcal{Q}_{0.75}$ & $0.3913 * * *$ & $0.3988 * * *$ & $0.3619 * * *$ & $0.2151 * * *$ & $0.1591 * * *$ & $0.1675^{* * * *}$ & $0.1652 * * *$ \\
\hline $\mathcal{Q}_{0.90}$ & $0.3913 * * *$ & $0.3988 * * *$ & $0.3566^{* * *}$ & $0.1582 * * *$ & $0.1583 * * *$ & $0.1654 * * *$ & $0.1652 * * *$ \\
\hline $\mathcal{Q}_{0.95}$ & $0.3732 * * *$ & $0.3794 * * *$ & -0.0700 & $0.1134 * * *$ & $0.1520 * * *$ & $0.1626 * * *$ & $0.1652 * * *$ \\
\hline $\begin{array}{l}\text { Cumulative } \\
\text { impact }\end{array}$ & 2.2011 & 2.3725 & 1.6937 & 1.2082 & 1.0290 & 1.0201 & 0.9666 \\
\hline
\end{tabular}

The table provides estimates of the slope coefficient $\beta_{1}(\theta, \tau)$ regressing the $\theta$-quantile, $\theta=$ $[0.05,0.10,0.250 .50,0.75,0.90,0.95]$ of the $\Delta \ln Y$ on the $\tau$-quantile, $\tau=[0.05,0.10,0.250 .50,0.75$, $0.90,0.95]$ of $\Delta \ln T$. We employ the wild bootstrap method developed by Feng et al. (2011) to calculate the $p$-values

$*, * *, * * *$ denote significance at $10 \%, 5 \%$ and $1 \%$ level respectively

the analysis shows that we have strong indications to support the argument that tourism contributes to output during low income periods.

\section{Conclusions and policy implications}

The paper provides fresh empirical evidence on the tourism-economic growth relationship. The case of Greece, a country relying on tourism, over the period 1977Q1-2020Q2 is taken as an example for our empirical investigation. Initially, we examine the existence of a non-linear relationship between tourism and output through the application of a threshold cointegration and an asymmetric error-correction model. Then, we examine the effects of tourism changes on output using quantile regression analysis. QR model estimation allows examining the impact of tourism changes over a range of values of output providing a more concrete investigation of the relationship of the two variables across the output distribution.

The results are as follows. First, we document that the long-run relationship between tourism and output is positive and is characterized by a substantially faster convergence of output after a negative shock than after a positive one. Second, the asymmetric error-correction model analysis shows that in the short term the adjustment path occurs through output for negative deviations from the long-run equilibrium. Consequently, the adjustment process is carried out though the modification of output supporting the tourism-led growth hypothesis for Greece, a finding similar to Dritsakis (2004) and Eeckels et al. (2012). Our findings add to the relevant literature in that tourism contributes to a faster output adjustment after a negative shock, and reduces the intensity of output fall, thus ensuring a more rapid absorption of the negative shock. Third, linear QR analysis shows that the impact of tourism is positive across the state 
of output. The magnitude of the effect is more pronounced and statistically significant at the lower quantiles of the output distribution that is in a bearish economy. Fourth, the asymmetric QR analysis shows that tourism growth exhibits asymmetric impact on output growth. In particular, the magnitude of the positive impact of tourism is relatively more intense at the lower levels of the output distribution.

Our findings have important policy implications, since the effects of tourism changes are not uniform throughout the output distribution and findings based on linear methodology may be misleading to policymaking. Tourism-led growth hypothesis, validated by our results, is a useful policy recommendation but it should not be considered a cure-all policy.

Positive tourism shocks and active tourism policies greatly facilitate the recovery of a weak economy since tourism activity has the flexibility to increase capacity utilization and absorb unemployment. In the case of a booming economy positive tourism shocks might be less effective, since there are fewer economic slacks to be absorbed by the tourism sector. Instead, other policy options gain importance, such as structural reforms, the creation of business-friendly environment to attract foreign investment, the upgrading of human capital and the promotion of technology advances. Finally, over the COVID-19 period, the halt in tourism deprived policymakers of a significant tool for a quick boost of output. Under these circumstances, apart from the mentioned policy options, a fiscal and liquidity backstop of a sizable amount (e.g. the European Recovery Fund) is necessary for the relaunching of the economy.

Acknowledgements The views expressed are those of the authors and not those of their respective institutions. The authors are grateful to Stephen Hall and two anonymous referees for helpful comments and suggestions.

\section{References}

Andriotis K (2002) Scale of hospitality firms and local economic development-evidence from Crete. Tour Manag 23(4):333-341

Antonakakis N, Dragouni M, Filis G (2015) How strong is the linkage between tourism and economic growth in Europe? Econ Model 44:142-155

Aslan A (2013) Tourism development and economic growth in the Mediterranean countries: Evidence from Panel Granger causality tests. Curr Issues Tour 17:363-372

Balaguer J, Cantavella-Jordá M (2002) Tourism as a long-run economic growth factor: The Spanish Case. Appl Econ 34:877-884

Bank of Greece (2019) "Developments and prospects of inbound tourism, 2010-2019”, Interim Report on Monetary policy, Box IV.3, 102-108

Bera AK, Galvao AF, Wang L, Xiao Z (2016) A new characterization of the normal distribution and test for normality. Econ Theory 32:1216-1252

Brida J, Cortés-Jiménez I, Pulina M (2016) Has the tourism-led growth hypothesis been validated? A literature review. Curr Issues Tour 19(5):394-430

Brock WA, Dechert WD, Scheinkman JA, LeBaron B (1996) A test for independence based on the correlation dimension. Economet Rev 15:197-235

Cárdenas-García PJ, Sánchez-Rivero M, Pulido-Fernández JI (2015) Does tourism growth influence economic development? J Travel Res 54:206-221 
Chan KS (1993) Consistency and limiting distribution of the least squares estimator of a threshold autoregressive model. Ann Stat 21(1):520-533

Comerio N, Strozzi S (2019) Tourism and its economic impact: a literature review using bibliometric tools. Tour Econ 25:109-131

Dritsakis N (2004) Tourism as a long-run economic growth factor: An empirical investigation for Greece using causality analysis. Tour Econ 10(3):305-316

Dritsakis N (2012) Tourism development and economic growth in seven Mediterranean countries: A panel data approach. Tour Econ 18(4):801-816

Eeckels B, Filis G, Leon C (2012) Tourism income and economic growth in Greece: empirical evidence from their cyclical components. Tour Econ 18(4):817-834

Enders W, Siklos PL (2001) Cointegration and threshold adjustment. J Bus Econ Stat 19(2):166-176

European Commission (2018) Enhanced surveillance report-Greece, Staff Working Document SWD (2018) 508, November

Feng X, He X, Hu J (2011) Wild bootstrap for quantile regression. Biometrika 98(4):995-999

Giannitsis T (1993) Industrial and Technological Policy in Greece. Themelio, Athens (in Greek)

Halikias D (1978), Money and Credit in a Developing Economy: The Case of Greece, New York University Press

Heckman JJ, Smith J, Clemens N (1997) Making the most out of programme evaluations and social experiments: accounting for heterogeneity in programmes impacts. Rev Econ Stud 64(4):487-535

Jackman M, Lorde T (2010) On the relationship between tourist flows and household expenditure in Barbados: A dynamic OLS approach. Econ Bull 30:1-9

Kasimati E (2011) Economic impact of tourism on Greece's economy: Cointegration and causality analysis. Int Res J Finance Econ 79:79-85

Kasimati E, Sideris D (2015) Towards a new development pattern in tourism: structural reforms and tourism product in Greece during the economic crisis (2008-2014). Econ Bull, Bank of Greece 42:7-20 (in Greek)

Katircioglu ST (2009) Revising the tourism-led growth hypothesis for Turkey using the bounds test and Johansen approach for cointegration. Tour Manag 30:17-20

Kim HJ, Chen MH, Jang SC (2006) Tourism expansion and economic development: The case of Taiwan. Tour Manag 27:925-933

Koenker R, Bassett G Jr (1978) Regression quantiles. Econometrica 46(2):33-50

Krueger A (1980) Trade policy as an input to development. Am Econ Rev 70:188-292

Lee J, Strazicich MC (2013) Minimum LM unit root test with one structural break. Econ Bull 33(4):2483-2492

Lolos S (1998) Success and failure of economic policies: The experience of Greece and Portugal. Comp Econ Stud 40:72-102

Massidda C, Mattana P (2013) A SVECM analysis of the relationship between international tourism arrivals, GDP and trade in Italy. J Travel Res 52(1):93-105

McKinnon R (1964) Foreign exchange constrain in economic development and efficient aid allocation. Econ J 74:388-409

Narayan PK (2004) Fiji's tourism demand: the ARDL approach to cointegration. Tour Econ 10(2):193-206

Nunkoo R, Seetanah B, Jaffur ZRK, Moraghen PGW, Sannassee RV (2019) Tourism and economic growth: A Meta-regression analysis. J Travel Res May, 1-20

Nusair SA, Olson D (2019) The effects of oil shocks on Asian exchange rates: Evidence from quantile regression analysis. Energy Econ 78:44-63

Oh C-O (2005) The contribution of tourism development to economic growth in the Korean economy. Tour Manag 26(1):39-44

Othman R, Salleh NHM, Sarmidi T (2012) Analysis of causal relationship between tourism development, economic growth and foreign direct investment: An ARDL approach. J Appl Sci 12(12):1245-1254

Payne JE, Mervar A (2010) Research note: The tourism-growth nexus in Croatia. Tour Econ 16(4):1089-1094

Ridderstaat J, Croes R, Nijkamp P (2013) Tourism and long-run economic growth in Aruba. Int J Tour Res 16(5):472-487

Schubert FS, Brida JG, Risso WA (2011) The impacts of international tourism demand on economic growth of small economies dependent of tourism. Tour Manag 32(2):377-385

Shahzad SJH, Shahbaz M, Ferrer R, Kumar RR (2017) Tourism-led growth hypothesis in the top ten tourist destinations: New evidence using the Quantile-on-Quantile approach. Tour Manag 60:223-232 
Shahbaz M, Zakaria M, Shahzad SJH, Mahalik MK (2018) The energy consumption and economic growth nexus in top ten energy-consuming countries: Fresh evidence from using the quantile-on quantile approach. Energy Econ 71:282-301

Sim N, Zhou H (2015) Oil prices, US stock return, and the dependence between their quantiles. J Bank Finance 55:1-8

Sun C (2011) Price dynamics in the import wooden bed market of the United States. For Policy Econ 13(6):479-487

Tang CF (2013) Temporal Granger causality and the dynamic relationship between real tourism receipts, real income, real exchange rates in Malaysia. Int J Tour Res 15(3):272-284

Zivot E, Andrews DWK (1992) Further evidence on the Great Crash, the oil-price shock, and the unitroot hypothesis. J Bus Econ Stat 10(3):251-270

Wang YS (2012) Research note: Threshold effects on development of tourism and economic growth. Tour Econ 18(5):1135-1141

Publisher's Note Springer Nature remains neutral with regard to jurisdictional claims in published maps and institutional affiliations. 